\title{
Pork meat quality after exposure to low (0.5 Gy) dose of gamma radiation
}

\author{
Petr Dvořák ${ }^{1}$, Katarína Beňová ${ }^{2}$, Dionýz Máté $^{3}$, Martin Tomko², Jana Doležalová ${ }^{1}$ \\ ${ }^{1}$ University of Veterinary and Pharmaceutical Sciences Brno, Faculty of Veterinary Hygiene and Ecology, \\ Department of Gastronomy, Centre for Ionizing Radiation Application, \\ ${ }^{2}$ University of Veterinary Medicine and Pharmacy in Kosice, \\ Institute of Biology, Zoology and Radiobiology, Brno, Czech Republic \\ ${ }^{3}$ University of Veterinary Medicine and Pharmacy in Kosice, \\ Institute of Meat Hygiene and Technology Kosice, Slovak Republic
}

Received March 14, 2019

Accepted October 29, 2019

\begin{abstract}
Farm animals in the immediate vicinity of damaged nuclear facilities (Chernobyl, Fukushima), may be affected by an external radiation dose and a radiation dose from internal contamination. In the experiment, pigs weighing $30 \mathrm{~kg}$ were exposed to a full body irradiation $\left({ }^{60} \mathrm{Co}\right)$ at a dose of 0.5 Gy. Samples from longissimus dorsi muscles at the last rib and semimembranosus muscles were collected. No significant differences of monitored meat colour indicators $\mathrm{L}^{*}, \mathrm{a}^{*}, \mathrm{~b}^{*}, \mathrm{C}^{*}, \Delta \mathrm{E}^{*}, \mathrm{pH}$ value, (45 min and $24 \mathrm{~h}$ post mortem) lactic acid concentration, water content and fat content ( 24 $\mathrm{h}$ post mortem) and drip loss indicators ( 24 and $48 \mathrm{~h}$ post mortem) between the experimental and control group (10 and 10 pigs, respectively) were observed. If there is no internal contamination, and external radiation dose does not exceed $0.5 \mathrm{~Gy}$, pigs from the affected area may be used for slaughter purposes. The results show that oxidative stress resulting from exposure to this dose of ionizing radiation does not affect the meat quality.
\end{abstract}

Ionizing radiation, pig, meat colour, food safety

Nowadays, more and more emphasis is given on studying the effects of low doses of ionizing radiation on living organisms. In the case of a whole body exposure, the imaginary borderline between stochastic and deterministic effects of ionizing radiation on humans and pigs represents a dose of $0.5 \mathrm{~Gy}$. Consequences of farm animals being exposed to ionizing radiation (Chernobyl, Fukushima) affecting food safety are still present (Kostiainen 2007; Beňová et al. 2016). Mainly farm animals in the immediate vicinity of the damaged nuclear facilities may be affected by an external radiation dose and a radiation dose from internal contamination (Ohmori et al. 2014).

Animals in the ex-evacuation zone might have experienced some changes owing to radioactive materials, including contaminated soil, small animals, and insects. It has been demonstrated that some changes in gene expression occurred in the small intestine of wild boar in the ex-evacuation zone after irradiation (Morimoto et al. 2017). It is difficult to conclude that these alterations are caused by only artificial radionuclides from the Fukushima Daiichi Nuclear Power Plant.

External exposure to ionizing radiation causes oxidative stress that accelerates lipid peroxidation of polyunsaturated fatty acids liberating alkanes and alkane metabolites (Phillips et al. 2015). Meat represents muscle tissue in a state of degradation. Degradation reactions generate free radicals, especially from unsaturated fatty acids, which are highly reactive. In the muscle, or rather, in meat as such, membranes maintaining mitochondrial integrity (and indeed the entire muscle cell) are more susceptible to the action of radicals, and subsequently to the degradation of cellular components. These processes accelerate metmyoglobin formation and change the levels of myoglobin, haemoglobin and cytochromes, affecting the meat colour (Young and West 2001; Bekhit and Faustman 2005). 
Meat quality is, however, affected by many other intravital factors such as stress during the transport and pre-slaughter treatment (Warris et al. 1994; D'Souza et al. 1998), structure of muscle fibres (Ryu and Kim 2005), and nutrition (Lindahl et al. 2006).

As demonstrated in previous experiments where 10,000-fold higher doses of ionizing radiation $(5 \mathrm{kGy})$ were used, the cell membrane's integrity is directly associated with the drip loss (Dvořák et al. 2004); however, no significant reduction in the tissue enzyme activity was noted (Dvořák et al. 2006).

Because ionizing radiation causes oxidative stress, a higher incidence of meat with an atypical maturation pattern such as PSE (Pale Soft Exudative) or others cannot be ruled out. On the other hand, the actual whole-body dose is important, with relatively lower doses not necessarily causing this negative effect.

The aim of this study was to determine whether a whole-body irradiation exposure to a doseof 0.5 Gy will have a negative impact on selected pig meat quality indicators.

\section{Materials and Methods}

The experiment was approved by the Ethics Committee in Slovakia in 2007 (7/2007/EK). A total of 20 pigs of the Slovak Large White breed (Sus scrofa domestica) were included in the experiment. Pigs were divided randomly into two groups of 10 animals (an experimental and a control group). Both groups consisted of gilts and barrows at a ratio of 50:50. At the beginning of the experiment, the pigs were at 2 months of age, weighing $30 \mathrm{~kg}$. They were housed in holding pens (separate for experimental and control groups) with access to daylight, and were reared under standard conditions. During the experiment, a standard pig feed mixture OS 03 for the corresponding age category was administered. Water and food were available ad libitum at nipple drinkers and food dispensers. Pig handling and transport in both the control and the experimental group were identical, except for irradiation. In order to reduce the effects of other stress factors, two weeks prior to irradiation pigs of both the control and the experimental group were repeatedly placed in irradiation cages and to the transport lorry for adaptation. No animal died during the experiment.

The experiment was performed in August. The pigs were mounted in cages appropriate to their size. Anaesthetics were not used during the experiment. The distance was determined by the Chisostat irradiation machine so that the gamma dose was homogeneous throughout the body. Ten pigs from the experimental group were irradiated by a single whole-body dose of $0.5 \mathrm{~Gy}$ gamma radiation ${ }^{60} \mathrm{Co}$, at a dose rate of $0.98 \mathrm{~Gy} \cdot \mathrm{h}^{-1}$. The other 10 pigs represented the control group. Irradiation was performed at the Faculty of Science, of the Pavol Jozef Safarik University in Kosice, Slovakia, located $35 \mathrm{~km}$ away from the farm by a device CHISOSTAT (Chirana, Czech Republic). Three days after irradiation, the pigs were transported to the slaughterhouse in Zemplínska Teplica (UVMP in Kosice) located just one $\mathrm{km}$ from the farm. After a rest period of $3 \mathrm{~h}$ at the slaughterhouse they were slaughtered. Electric prods were not used either during the pig housing, or during the loading and unloading. In case of a real accident, the evacuation of pigs is carried out within three days, therefore the same experiment time was determined.

Pigs were slaughtered and samples of the longissimus dorsi (LD) muscle at the last rib and of the semimembranosus (SM) muscle were collected.

Muscle (meat) $\mathrm{pH}$ value and colour were measured at $45 \mathrm{~min}$ and $24 \mathrm{~h}$ post mortem. The $\mathrm{pH}$ value was measured using the Orion $250 \mathrm{~A}+$ digital $\mathrm{pH}$ meter equipped with an Orion puncture electrode. Calibration was performed on three buffers of $\mathrm{pH} 4.01 ; 7.00$ and 9.00 . The $\mathrm{pH}$ value was recorded after the automatically measured value got stabilized.

Meat colour was determined in the CIELAB system using the portable Colour-guide sphere spex spectrophotometer (BYK Gardner, Germany), excluding gloss, using a spherical geometry $\mathrm{d} / 8^{\circ}, \mathrm{D}_{65}$ as a source of light, the standard observer's angle set to $10^{\circ}$, and the diameter of the opening being $8 \mathrm{~mm}$. The instrument was calibrated to the food foil prior to measurement.

Meat colour at the cut perpendicular to the muscle fibres was determined by using the mean of the values collected from three separate measurements (CIE 1986). For comparative studies it is essential to maintain a precise instrumentation (Brewer et al. 2001); similarly, in determining the $\mathrm{pH}$ value (Henckel et al. 2000).

In order to compare the results, further indicators of the CIELAB system were calculated from the mean values of L* (Lightness), a* (Redness), b* (Yellowness) coordinates (Honikel 1998). The distance between the two points, $\Delta \mathrm{E}^{*}$ (CIE total colour difference) was calculated according to the formula:

$\Delta E^{*}=\left[\left(\Delta L^{*}\right)^{2}+\left(\Delta a^{*}\right)^{2}+\left(\Delta b^{*}\right)^{2}\right]^{1 / 2}$.

The total colour difference $\left(D E^{*}\right)$ aggregate values of all the three above mentioned indicators $L^{*}, a^{*}$ and $b^{*}$.

The chroma $\mathrm{C}^{*}$ ab is a value that indicates the difference between the respective value of colour and the grey colour, according to the formula:

$\mathrm{C}_{\mathrm{ab}}^{*}=\left(a^{* 2}+b^{* 2}\right)^{1 / 2}$.

Determination of drip loss was carried out by a standard method within the time period from 24 to $48 \mathrm{~h}$ post mortem, and also by a modified method using a container (Dvořák and Mikulík 1990; Honikel 1998) within 
the time period from 0 to $24 \mathrm{~h}$ post mortem. Measurement of the lactic acid concentration was performed $24 \mathrm{~h}$ post mortem. The lactate content was determined spectrophotometrically $(340 \mathrm{~nm})$ using a commercial kit for the determination of lactic acid. Approximately $500 \mathrm{mg}$ of muscle was homogenized for $30 \mathrm{~s}$ in $2 \mathrm{ml}$ of $1 \mathrm{M}$ PCA. Potassium hydroxide $(2 \mathrm{M}$ ) was added to neutralize the solution, and the final volume was made to $10 \mathrm{ml}$ with distilled water. Following $20 \mathrm{~min}$ of refrigeration and centrifugation, the lactic acid concentration was measured (Choe and Kim 2014).

Determination of the water content and fat content was performed according to AOAC 2003 ( $24 \mathrm{~h}$ post mortem).

Two-sample $t$-test with unequal variances was used for average difference significance testing in both the experimental and the control group. Paired $t$-test was used for comparing average values at different locations of LD muscle or against SM muscle. Paired $t$-test was also applied for testing the differences of the values 45 min and $24 \mathrm{~h}$ post mortem. Due to the expected variability, a significance level of $P<0.05$ was determined in the planning of experiments for all hypotheses. Statistical values were calculated by MS Excel.

Table 1. Meat quality indicators of longissimus dorsi and semimembranosus muscles in the control (10 pigs) and experimental groups (10 pigs) after total body irradiation by $0.5 \mathrm{~Gy}$.

\begin{tabular}{|c|c|c|c|c|}
\hline \multirow[b]{2}{*}{ Indicator } & \multicolumn{2}{|c|}{ Musculus longissimus dorsi } & \multicolumn{2}{|c|}{ Musculus semimembranosus } \\
\hline & $\begin{array}{c}\text { Irradiated group } \\
(\text { mean } \pm \mathrm{SEM})\end{array}$ & $\begin{array}{l}\text { Control group } \\
(\text { mean } \pm \text { SEM })\end{array}$ & $\begin{array}{c}\text { Irradiated group } \\
(\text { mean } \pm \mathrm{SEM})\end{array}$ & $\begin{array}{l}\text { Control group } \\
(\text { mean } \pm \text { SEM })\end{array}$ \\
\hline $\mathrm{pH}_{45}$ & $6.01 \pm 0.08$ & $5.93 \pm 0.12$ & $6.01 \pm 0.08$ & $6.11 \pm 0.10$ \\
\hline $\mathrm{pH}_{24}$ & $5.53 \pm 0.02$ & $5.53 \pm 0.06$ & $5.56 \pm 0.03$ & $5.61 \pm 0.01$ \\
\hline $\mathrm{L}^{*}{ }_{45}^{24}$ & $43.39 \pm 1.16$ & $45.92 \pm 1.27$ & $42.36 \pm 1.25$ & $42.44 \pm 1.94$ \\
\hline $\mathrm{L}^{*}{ }_{24}^{43}$ & $55.48 \pm 0.52$ & $54.84 \pm 1.04$ & $50.93 \pm 0.63$ & $49.26 \pm 1.60$ \\
\hline $\mathrm{a}^{*}{ }_{45}^{24}$ & $-1.01 \pm 0.31$ & $-0.87 \pm 0.46$ & $1.72 \pm 0.89$ & $3.03 \pm 0.78$ \\
\hline $\mathrm{a}^{*}{ }_{24}^{43}$ & $0.08 \pm 0.30$ & $-0.73 \pm 0.32$ & $2.52 \pm 0.50$ & $4.05 \pm 1.20$ \\
\hline $\mathrm{b}^{24}{ }_{45}$ & $4.47 \pm 0.32$ & $4.77 \pm 0.43$ & $6.26 \pm 0.30$ & $6.14 \pm 0.68$ \\
\hline $\mathrm{b}^{*}{ }_{24}$ & $6.95 \pm 0.30$ & $6.32 \pm 0.41$ & $7.31 \pm 0.40$ & $7.01 \pm 0.36$ \\
\hline$\Delta \mathrm{E}^{*}{ }_{45}$ & $37.58 \pm 1.14$ & $36.48 \pm 1.66$ & $39.26 \pm 1.43$ & $38.58 \pm 1.89$ \\
\hline$\Delta \mathrm{E}^{*}{ }_{24}$ & $26.78 \pm 0.47$ & $27.04 \pm 1.03$ & $31.85 \pm 0.64$ & $34.10 \pm 1.91$ \\
\hline $\mathrm{C}^{*}{ }_{45}^{24}$ & $4.67 \pm 0.32$ & $5.04 \pm 0.42$ & $6.94 \pm 0.44$ & $7.17 \pm 0.75$ \\
\hline $\mathrm{C}^{*}{ }_{24}$ & $7.01 \pm 0.30$ & $6.46 \pm 0.38$ & $7.86 \pm 0.43$ & $8.62 \pm 0.78$ \\
\hline Water $(\%)$ & $74.81 \pm 0.27$ & $76.42 \pm 0.29$ & $75.30 \pm 0.25$ & $74.62 \pm 0.48$ \\
\hline Fat $(\%)$ & $3.63 \pm 0.29$ & $3.23 \pm 0.20$ & $4.56 \pm 0.21$ & $5.04 \pm 0.56$ \\
\hline Drip loss $\quad(0-24 \mathrm{~h}[\%])$ & $2.03 \pm 0.29$ & $1.97 \pm 0.24$ & $1.44 \pm 0.20$ & $1.47 \pm 0.19$ \\
\hline Drip loss $(24-48 \mathrm{~h}[\%])$ & $2.00 \pm 0.23$ & $2.06 \pm 0.26$ & $1.46 \pm 0.20$ & $1.50 \pm 0.19$ \\
\hline Lactic acid $\left[\mathrm{g} \cdot \mathrm{kg}^{-1}\right]$ & $14.13 \pm 0.69$ & $13.84 \pm 0.44$ & $14.09 \pm 0.50$ & $13.91 \pm 1.29$ \\
\hline
\end{tabular}

Mean - arithmetical mean; SEM - standard error of the mean; L*, a*, b*, $\Delta \mathrm{E}^{*}, \mathrm{C}^{*}$ - meat colour indicators (CIELAB); Subscript ${ }_{45}-45$ min post mortem; Subscript ${ }_{24}-24 \mathrm{~h}$ post mortem

\section{Results}

Results are summarized in Table 1. No significant differences between the experimental and control groups in the monitored meat quality indicators were found. The $\mathrm{pH}$ values in the control and experimental groups were practically the same for both studied muscles, showing a well-known significant $\mathrm{pH}$ decline at $24 \mathrm{~h}$ post mortem.

The meat colour indicator $\mathrm{L}^{*}$ at $24 \mathrm{~h}$ post mortem substantially increased in all cases. Significant differences $(P<0.05)$ in the meat colour indicator $\mathrm{L}^{*}$ between the LD and SM muscles were found only at $24 \mathrm{~h}$. As common, longissimus dorsi muscles were lighter. For the a* value there was no significant increase at $24 \mathrm{~h}$ post mortem. The a* value in SD muscles was significantly higher $(P<0.05)$. It corresponds with the more reddish colour of thigh meat compared to the cutlet. The colour indicator $b^{*}$ was significantly increased $(P<0.05)$ at $24 \mathrm{~h}$ post mortem only in the LD muscle. In comparison, in SM muscles the $\mathrm{b}^{*}$ 
indicator value was significantly higher only at $45 \mathrm{~min}$ post mortem; however, at $24 \mathrm{~h}$ the differences were no longer significant. Conversely, the $\Delta \mathrm{E}^{*}$ (CIE total colour difference) indicator in the SM muscle reached a significantly higher value only at $24 \mathrm{~h}$ post mortem. The overall decrease of this indicator at $24 \mathrm{~h}$ was significant in the LD muscles of both groups and in the SM muscles of the irradiated group. The SM muscle $\Delta \mathrm{E}^{*}$ indicator decrease in the control group was not significant.

Indicator $\mathrm{C}^{*}$ indicates differences in the shade of the grey colour. The semimembranosus muscle, with the exception of the irradiated group, showed a significantly higher indicator $\mathrm{C}^{*}$ value at $24 \mathrm{~h}$ post mortem compared to the $\mathrm{LD}$ muscle. However, by meat aging, an increase in the indicator $\mathrm{C}^{*}$ value was only seen in the LD muscle, whereas in the SM muscle the increase was non-significant. Our results also show that regarding colour indicators, the LD muscle is more sensitive compared to SM.

In terms of the methods used, it is interesting to note that the drip loss was virtually identical in both the $0-24 \mathrm{~h}$ and the $24-48 \mathrm{~h}$ interval.

No significant differences were found between the irradiated and control groups in the water content, fat content and drip loss.

The results of the lactic acid concentration in both the LD muscles and the SM muscles show non-significantly higher values in irradiated pigs. As our study shows, a 0.5 Gy whole-body dose does not negatively affect meat quality indicators.

\section{Discussion}

Low doses of ionizing radiation up to 0.5 Gy represent an approximate boundary between the stochastic and deterministic effects of ionizing radiation in both humans and pigs. Stochastic effect in particular cause a higher incidence of oncological diseases, which in the case of slaughter animals has no practical impact. However, these doses may already represent an oxidative stress.

In general, any stress (transport, pre-slaughter activities, etc.) represents a key factor of the PSE meat defects (Van de Perre et al. 2010), which are in particular reflected in the changes of: $\mathrm{pH}$ indicators (Schefller and Gerrard 2007), meat colour, drip juice loss (Šimek et al. 2004; Kameník et al. 2018), and lactic acid concentrations.

Changes of the above mentioned indicators could be related to changes in the cell protein profile after exposure to ionizing radiation. For example: PUMA (p53 upregulated modulator of apoptosis) regulates apoptosis by controlling the permeability of the external mitochondrial membrane and is changed already at a dose of 0.5 Gy (Zhang et al. 2001).

In fresh red meat, myoglobin occurs in three chemical forms. Surface colour changes of meat are initiated by meat exposure to oxygen, and among other things, are caused by changes in the content of the chemical forms of myoglobin, e.g. oxygenated myoglobin (oxymyoglobin), oxidized myoglobin (metmyoglobin), and reduced myoglobin (deoxymyoglobin) (Karamucki et al. 2011). Pink deoxymyoglobin, after exposure to air, is rapidly oxidized to red coloured oxymyoglobin, which is sequentially oxidized to brown metmyoglobin (Bekhit and Faustman 2005; Pavelková and Flimelová 2012).

The activity of the metmyoglobin reductase enzyme can reduce brown metmyoglobin to pinkish-red deoxymyoglobin. The factors affecting redox activity include the process of animals feeding and their opportunity to move, temperature, time, $\mathrm{pH}$, oxidation of lipids, oxygen content, presence of different chemical elements, influence of light and nucleotides, species diversity and difference in muscles of harvested animals (Livingston and Brown 1981). A decrease in the metmyoglobin reductase activity cannot be ruled out, as the activity of some other enzymes has been demonstrated in the same experiment (Smutná et al. 2013). Scheffler and Gerrard (2007) pointed out the crucial importance of enzymes in post mortem energy metabolism. 
The higher values of $\Delta \mathrm{E}^{*}$ and $\mathrm{C}^{*}$ indicators at $24 \mathrm{~h}$ correspond to the meat aging of the LD muscle. Exposure of pigs to radiation had no significant effect on the value of these indicators (Table 1). Absolute values of lactic acid concentration or colour indicators in our study differ from findings of others authors (Choe et al. 2008; Kameník et al. 2018).

Advanced technologies of pig rearing should prevent significant internal contamination of pigs with radionuclides. Affected pigs can be transported to distant slaughterhouses and used for further processing after standard decontamination by water showering (Petäjä et al. 1992). It can be assumed that during an accident of a nuclear power plant, animals (pigs) from the farms located in the power plant protected zone, will not be exposed to whole body irradiation exceeding a dose of $0.5 \mathrm{~Gy}$.

Thanks to modern technologies in pig farming, it is possible for a certain time period to significantly reduce internal contamination of slaughter pigs by radionuclides. Additionally, even in internally contaminated pigs, there is a possibility to reduce internal contamination by the use of common meat processing technologies (Jandl et al. 1989; Dvořák et al. 2008).

In conclusion, total body exposure of pigs to irradiation by a single whole-body dose of $0.5 \mathrm{~Gy}$ does not affect the quality of pork meat. In a case of a nuclear accident, unless there is no internal contamination, and the effective dose does not exceed $0.5 \mathrm{~Gy}$, pigs from the exposed area may be used for meat production.

\section{References}

AOAC International. Official Methods of Analysis of AOAC International. $17^{\text {th }}$ Edn. $2^{\text {nd }}$ Rev. Association of Analytical Communities, Gaithersburg, 2003

CIE 1986: Colorimetry. $2^{\text {nd }}$ Edn, CIE Publications No. 15.2. Commission Internationale de l'Eclaraige, Vienna

Bekhit AED, Faustman C 2005: Metmyoglobin reducing activity. Meat Sci 71: 407-439

Beňová K, Dvořák P, Tomko M, Falis M 2016: Artificial environmental radionuclides in Europe and methods of lowering their foodstuff contamination - a review. Acta Vet Brno 85: 105-112

Brewer MS, Zhu LG, Bidner B, Meisinger DJ, McKeith FK 2001: Measuring pork color: effects of bloom time, muscle, $\mathrm{pH}$ and relationship to instrumental parameters. Meat Sci 57: 69-76

Choe JH, Choi YM, Lee SH, Shin HG, Ryu YC, Hong KC, Kim BC 2008: The relation between glycogen, lactate content and muscle fiber type composition, and their influence on postmortem glycolytic rate and pork quality. Meat Sci 80: 355-362

Choe JH, Kim BC 2014: Association of blood glucose, blood lactate, serum cortisol levels, muscle metabolites, muscle fiber type composition, and pork quality traits. Meat Sci 97: 137-142

D'Souza DN, Dunshea FR, Warner RD, Leury BJ 1998: The effect of handling pre-slaughter and carcass processing rate post-slaughter on pork quality. Meat Sci 50: 429-437

Dvoř́a P, Grolichová M, Musilová H 2004: Einfluss der ionisierenden Sthrahlung auf die Farbe und Tropfsaftverlust von Schweinefleisch. Fleischwirtschaft 11: 122-124

Dvořák P, Kunová V, Kunová J, Beňová K 2008: Radiocesium activity reduction in boar meat by brining. Radiat Environ Bioph 47: 179-182

Dvořák P, Mikulík A 1990: The effect of chemically preserved blood feeding on reduction of the incidence of PSE meat [In Czech]. Czech J Anim Sci 35: 745-751

Dvořák P, Šalplachta J, Zima S, Grolichová M, Musilová H 2006: The effect of ionizing radiation on tissue enzymes. B Vet I Pulawy 50: 221-223

Henckel P, Karlsson A, Oksbjerg N, Petersen JS 2000: Control of post mortem pH decrease in pig muscles: experimental design and testing of animal models. Meat Sci 55: 131-138

Honikel KO 1998: Reference methods for the assessment of physical characteristics of meat. Meat Sci 49: 447-457

Kameník J, Saláková A, Kašpar L 2018: Characteristics of selected pork muscles 45 min and 24 h post mortem. Acta Vet Brno 87: 173-180

Jandl J, Novosad J, Francová H, Procházka H 1989: Caesium removal from deer meat [In Czech]. Vet Med-Czech 34: $485-490$

Karamucki T, Gardzielewska J, Rybarczyk A, Jakubowska M, Natalczyk-Szymkowska W 2011: Usefulness of selected methods of color change measurement for pork quality assessment. Czech J Food Sci 29: 212-218

Kostiainen E 2007: Cs-137 in Finnish wild berries, mushrooms and game meat in 2000 - 2005. Boreal Environ Res 12: 23-28

Lindahl G, Young JF, Oksbjerg N, Andersen HJ 2006: Influence of dietary creatine monohydrate and carcass cooling rate on color characteristics of pork loin from different pure breeds. Meat Sci 72: 624-634 
Livingston DJ, Brown WD 1981: The chemistry of myoglobin and its reactions. Food Tech 35: 244-252

Morimoto M, Kato A, Kobayashi J, Okuda K, Kuwahara Y, Kino Y, Abe Y, Sekine T, Fukuda T, Isogai E, Fukumoto M 2017: Gene expression analyses of the small intestine of pigs in the ex-evacuation zone of the Fukushima Daiichi Nuclear Power Plant. BMC Vet Res 13: 337, 1-8

Ohmori H, Sasaki Y, Tajima K, Katsumata M 2014: Radioactive caesium concentrations in pigs fed brown rice contaminated by the Tokyo Electric Power Company Fukushima Daiichi nuclear power plant. Livestock Sci 159: $156-160$

Pavelková A, Flimelová E 2012: Active packaging system for meat and meat products. Potravinarstvo 6: 21-27

Petäjä E, Rantavaara A, Paakola O, Puolanne E 1992: Reduction of radioactive cesium in meat and fish by soaking. J Environ Radioactiv 16: 273-285

Phillips M, Cataneo RN, Chaturvedi A, Kaplan PD, Libardoni M, Mundada M, Patel U, Thrall KD, Zhang $X$ 2015: Breath biomarkers of whole-body gamma irradiation in the Gottingen minipig. Health Phys 108: 538-546

Ryu YC, Kim BC 2005: The relationship between muscle fiber characteristics, postmortem metabolic rate, and meat quality of pig longissimus dorsi muscle. Meat Sci 71: 351-357

Scheffler TL, Gerrard DE 2007: Mechanisms controlling pork quality development: The biochemistry controlling postmortem energy metabolism. Meat Sci 77: 7-16

Smutná M, Beňová K, Dvořák P, Nekvapil T, Kopřiva V, Maté D 2013: Protein carbonyls and traditional biomarkers in pigs exposed to low-dose $\gamma$-radiation. Res Vet Sci 94: 214-218

Šimek J, Grolichová M, Steinhauserová I, Steinhauser L 2004: Carcass and meat quality of selected final hybrids of pigs in the Czech Republic. Meat Sci 66: 383-386

Van de Perre V, Ceustermans A, Leyten J, Geers R 2010: The prevalence of PSE characteristics in pork and cooked ham - Effects of season and lairage time. Meat Sci 86: 391-397

Warriss PD, Brown SN, Adams SJM, Corlett IK 1994: Relationships between subjective and objective assessments of stress at slaughter and meat quality in pigs. Meat Sci 38: 329-340

Young OA, West J 2001: Meat Color. In: Hui YH, Nip W-K, Rogers RW, Young OA, editors. Meat Science and Applications. New York: Marcel Dekker, Inc; pp. 39-69

Zhang XL, Zhao S, Borenstein SH, Liu Y, Jayabalasingham B, Chamberlain JWJ 2001: Links CD8 expression up to the double-positive CD3(low/intermediate)stage of thymic differentiation is sufficient for development of peripheral functional cytotoxic T lymphocytes. Exp Med 194: 685-693 